\title{
The whole is greater than the sum of its parts: profiles of multiple mental health risk factors using Latent class analysis
}

\author{
Kristin Göbel ${ }^{1,2^{*}}$ (1) and Caroline Cohrdes ${ }^{1}$
}

\begin{abstract}
Background: The exposure to an accumulation of various risk factors during childhood and adolescence relative to a single risk is associated with poorer mental health. Identification of distinct constellations of risk factors is an essential step towards the development of effective prevention strategies of mental disorders. A Latent class analysis (LCA) extracts different combinations of risk factors or subgroups and examines the association between profiles of multiple risk and mental health outcomes.
\end{abstract}

Methods: The current study used longitudinal survey data (KiGGS) of 10,853 German children, adolescents and young adults. The LCA included 27 robust risk and protective factors across multiple domains for mental health.

Results: The LCA identified four subgroups of individuals with different risk profiles: a basic-risk (51.4\%), high-risk (23.4\%), parental-risk (11.8\%) and social-risk class (13.4\%). Multiple risk factors of the family domain, in particular family instability were associated with negative mental health outcomes (e.g. mental health problems, depression, ADHD) and predominately comprised late adolescent girls. The social environment represented a more common risk domain for young males.

Conclusion: The understanding of multiple risk and different risk "profiles" helps to understand and adjust targeted interventions with a focus on vulnerable groups.

Keywords: Mental health, Youth, Multiple risk factors, Latent class analysis, Depression

\section{Background}

Mental health problems originate early in life, affect $10-20 \%$ of children and adolescents worldwide, and can have a long-lasting effect throughout life [1]. Empirical evidence shows that a number of mental health problems during childhood tend to continue or predict other problems in adulthood [2]. Attention deficit/hyperactivity disorder (ADHD) is one of the most common mental disorders in childhood and adolescence, while major

\footnotetext{
*Correspondence: Kristin.Goebel@fu-berlin.de

${ }^{1}$ Department of Epidemiology and Health Monitoring, Mental Health Unit, Robert Koch Institute, General-Pape-Straße 62-66, 12101 Berlin, Germany

Full list of author information is available at the end of the article
}

depression is more common during young adulthood. Both illnesses are related to an enormous disease burden for individual and society $[3,4]$. Hence a better understanding of the factors associated with mental health during childhood and adolescence is of great importance.

The presence of a single risk factor during childhood and adolescence is very common and associated with litthe to no developmental consequences $[5,6]$. According to the multiple risk perspective, the exposure to an accumulation of various risk factors relative to a single risk is associated with poorer mental health in children and adolescents, and described as a cause for mental disorders in young people $[2,5,7-9]$. The absence or presence of multiple risk factors explains why some children living in a single parent household may be adjusted well (i.e.

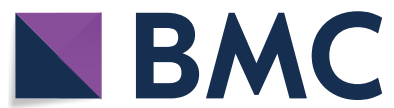

(c) The Author(s) 2021. This article is licensed under a Creative Commons Attribution 4.0 International License, which permits use, sharing, adaptation, distribution and reproduction in any medium or format, as long as you give appropriate credit to the original author(s) and the source, provide a link to the Creative Commons licence, and indicate if changes were made. The images or other third party material in this article are included in the article's Creative Commons licence, unless indicated otherwise in a credit line to the material. If material is not included in the article's Creative Commons licence and your intended use is not permitted by statutory regulation or exceeds the permitted use, you will need to obtain permission directly from the copyright holder. To view a copy of this licence, visit http://creativeco mmons.org/licenses/by/4.0/. The Creative Commons Public Domain Dedication waiver (http://creativecommons.org/publicdomain/ zero/1.0/) applies to the data made available in this article, unless otherwise stated in a credit line to the data. 
absence of multiple risks) and why some children with both parents may show developmental delays (i.e. presence of multiple negative events).

Fortunately, not all children who are exposed to multiple risk factors experience mental health problems as the presence of protective factors are equally relevant. Research found evidence that protective factors in various domains (e.g. personal, familial and social resources) buffered the adverse impact of multiple risk factors [5]. Protective factors contribute to a resilient development by strengthening children's mental health when being exposed to risks [9]. Furthermore, childhood and adolescence do not occur in isolation but rather within multiple domains, including the family, the school and the environment [1-3]. Multiple risk and protective factors can cumulate across those different domains. For instance, children living in a single parent household may receive significant social support as a buffer for maladjustment. With other words, the significance of any one aspect of individual development becomes meaningful when taking other aspects of the environment into account [10]. The nature and interplay of those factors across domains hinder or contribute to the development of mentally healthy individuals [2]. Albeit literature shows how each context can contribute to specific outcomes, far less is known about the multilevel impact regarding risk factors within diverse contexts. The purpose of the present study was to identify the subgroups of co-occurrence of multiple risk factors across domains in a young sample and their association with mental health outcomes.

\section{Risk factors for mental health}

Innumerous investigations of risk and protective factors for childhood and adolescence mental health exist and are commonly separated into three domains: individual, familial and social [9]. At the level of the individual, children's own characteristics like temperament $[5,11]$, self-esteem [12] or self-efficacy can have an effect on their mental health. For instance, high self-efficacy is the optimistic belief in one's own ability to be able to cope and adapt to difficult demands in life or stressful events, and has been associated with fewer adjustment problems [13]. Moreover, biological factors such as low birthweight (LBW) as well as prenatal exposure to alcohol and tobacco $[14,15]$, duration of breastfeeding [14, 16], chronic illnesses [17] and postnatal problems (e.g. adjustment or infections) $[18,19]$ have shown to contribute to negative mental health outcomes like developmental delays and behavioural disorders [6].

Apart from individual risk factors, familial factors are among the most significant predictors of negative mental health outcomes. Children's first contact with their environment begins with their parents who significantly contribute to their socialization of appropriate behaviour from infancy and beyond [20]. The quality of parenting has important consequences for a child's health outcomes [21]. Children exhibit less emotional and behavioural dysfunctioning if raised in authoritative homes with warmth, autonomy and clear rules [22]. For instance, Cohrdes and Göbel (submitted) examined a sample of 4,258 German adolescents with an age range of 11-17 years showing that parenting characterized by warmth was related to fewer behavioural problems, while pressure was related to a higher risk of behavioural and emotional problems. Likewise, a change in family structure for instance a transition from a two-parent to a single-parent family due to divorce is associated with more behavior and emotional problems [23]. Additionally, numerous studies have shown associations between several family factors and negative mental health outcomes, for instance teenage mothers [5, 24], large family size [25], low parental education [5, 26], low parental health [27], high parental stress [28] and parental psychopathology [29-31].

Furthermore, an accumulating body of research worldwide has focused on the complex, insidious problem of child maltreatment which is repeatedly linked to adverse mental and physical health. Child maltreatment involving physical or sexual abuse have been extensively studied as risk factors for adverse long-term outcomes, however also psychological abuse or neglect, has received increasing attention. Precisely, emotional neglect or abuse consists of behaviours towards children such as rejection, isolation, or verbal assault and have serious adverse effects on mental health [32-34].

In addition to risk factors originating within the family, the surrounding or social environment nearby exerts influences on children. For instance, as adolescents become increasingly independent, they begin to seek out peer relationships as source of intimacy and social support. Peer relationships offer support while exploring different roles or promoting self-disclosure [35]. Adverse social relations and experiences enhance the risk for mental disorders in youth [11]. For instance, a large body of research has shown that experiences with discrimination [36] or being teased by peers or family members are associated with a wide range of psychosocial problems, including aggressive behavior, anxiety, and depression [37]. In general, positive social networks contribute to the development of a child by encouraging coping and offering support $[9,35]$.

Substantial research has shown that multiple risk factors portend maladjustment in children and adolescents, thereby making an impact on the developmental course across adolescence and emerging adulthood [1-3]. 
Identification of distinct constellations of risk factors is an essential step to tackle differences in children's development over the life course and towards the development of effective prevention strategies of mental disorders [4, 5].

\section{Empirical approach towards multiple risk factors}

A general approach towards the understanding of multiple risk factors and child development used by several researchers is a variable-oriented method such as a cumulative risk index [9].

By using the sum of dichotomized risk factors to construct a cumulative risk index, Rutter [8] marked the beginnings of subsequent numerous investigations demonstrating the associations between multiple risks and less adaptive mental health outcomes [9, 20, 38]. For instance, Wille et al. [9] examined children's mental health and the number of potential risk and protective factors using a representative sub-sample of 2863 families with children and adolescents aged 7-17 years. Main findings suggest that the co-occurrence of risk factors affect mental health problems significantly. Parental health-related quality of life and conflicts within the family showed the strongest association with a child's mental health problems.

However, the cumulative risk index emphasizes two disadvantages. The approach treats multiple risk factors equally by giving each of them the same weight. Furthermore, multiple risk factors are substitutable, by which the pure exposure matters rather than the nature of the risk factors [39]. Moreover, an index does not provide enough information about the interaction between risk factors and its variation across distinct subgroups [39].

One complementary approach to the variable-oriented method is a person-centered approach such as the Latent class analysis (LCA). A LCA categorizes individuals into homogenous subgroups (or classes) within a heterogeneous population according to certain characteristics or patterns [40]. A person-centered approach can provide important insight regarding the interaction of the individual's entire range of risk factors and its association to less adaptive mental health outcomes [41]. In other words, the demonstration of different combinations of risk factors across multiple domains (i.e. individual, family, and social environment) provides a better understanding of the associations between risk factors and aversive mental health outcomes [39]. Despite the growing popularity of person-centered approaches as, several studies used LCA in different contexts (e.g. [42, 43, 44]), it has less well been demonstrated with regard to multiple risk factor for mental health across several domains. Previous studies have almost exclusively focused on single domains or cluster analysis as person-centered statistical technique. Amongst previous research, only two studies applied a person-centered method for modelling multiple mental health risks. Parra, DuBois, and Sher [45] identified four subgroups of adolescents (7th and 11th graders) with distinct profiles of risk factors (i.e. low risk, socioeconomic disadvantage, peer high risk, and family high risk class) from different contextual domains (i.e., individual, family, peer, school, and neighborhood) with predicted levels of depressive symptoms and conduct problems both concurrently and over time.

Lanza and colleagues [39] extracted four unique profiles with 13 risk factors across child, family, school, and neighborhood domains for preschool children $(\mathrm{N}=750)$. Results showed that the highest risk for negative outcomes are subgroups characterized by several risks across several domains.

However, several shortcomings were noted for these studies, for instance, (1) a restricted choice of risk factors (i.e. robust risk factors for mental health were not assessed); (2) no parent-report data were used (i.e. multiinformant data for a comprehensive assessment of youth functioning was not considered); and (3) no representative population or a small sample with a restricted age range was used for analyses.

In spite of those two studies using LCA to identify risk profiles with multiple risk factors across several domains, the topic is still insufficiently explored.

\section{The current study}

The focus of the current study was primarily on identifying homogeneous subgroups of adolescents according to their exposure to a broad range of mental health risk indicators with a large sample using a person-centered approach (e.g. LCA). We expected to find at least four subgroups of multiple risk combinations concurrent with previous research $[39,45]$. Furthermore, we hypothesized to identify subgroups that are not only distinct due to the number of risks (e.g. low, medium vs. high risk) as inferred by a variable-centered approach but also due to the nature of the risk factors (e.g. subgroup with familyrelated risks).

The second aim was to examine the extracted homogeneous subgroups and their associations with different mental health issues or disorders (i.e. internalizing and externalizing mental health problems, reported diagnoses of ADHD and depression). We hypothesized that subgroups characterized by multiple risks will show a high probability for negative mental health outcomes. Furthermore, we also expected subgroups characterized by specific risks to show different combinations of internalizing and externalizing mental health problems, reported diagnoses of ADHD and depression. Additionally, as reported by Fanti and Henrich [46], we expect 
externalizing problems more often to be found in early adolescent boys, and internalizing problems more prevalent in late adolescent girls.

The current study improves upon prior research by including key constructs known to be robust risk factors for adolescent psychopathology from multiple domains (i.e. individual, family, and social); using multiple informant information (i.e. self and parental reports); and lastly by conducting analyses with data from a large, national, and longitudinal German sample of children and adolescents.

The identification of distinct subgroups according to their multiple risk exposure and their relation to mental health outcomes can help to better identify vulnerable individuals with a special need and specific strategies of prevention and intervention.

\section{Methods \\ Sample}

The German Health Interview and Examination Survey for Children and Adolescents (KiGGS) is part of the federal health monitoring framework established at the Robert Koch- Institute. KiGGS incorporates several cross-sectional surveys (i.e. KiGGS Baseline, KiGGS Wave 1 and KiGGS Wave 2) with all waves collapsing to a longitudinal component (KiGGS Cohort). The current study reports on children, adolescents and young adults from the KiGGS Cohort, who across an eleven-year period completed at least two out of the three assessments (i.e. KiGGS Baseline and Wave 2). Two different publications describe the study design, sample information and attrition in more detail $[47,48]$.

In brief, starting in 2003, 0-17 year olds were recruited from 167 sample points across Germany providing information on a wide spectrum of health-relevant topics related to the child and the primary caregiver. Two follow-ups were initiated approximately 6 and 11 years later (KiGGS Wave 1: 2009-2012, KiGGS Wave 2: 20142017), obtaining wide-ranging, reliable data on child and adolescent health from birth to childhood and from adolescence to young adulthood. The final sample for this study (KiGGS Cohort) included data from 10,853 children, adolescents and young adults and their primary caregiver with an age range between 10 to 31 years (mean age $19.1, \mathrm{SD}=5.2$ ) and $44.6 \%$ females.

\section{Measures}

\section{Indicators}

The KiGGS Cohort study comprises a broad set of determinants including risk and protective factors for child and adolescent mental health. In line with previous research, several robust risk and protective factors for mental health were collected across three domains: individual (e.g. chronic illness, self-efficacy), familial (e.g. family cohesion, maltreatment), and social (e.g. social support, peer relation). Table 1 provides an overview of 27 selected indicators, corresponding measurement instruments, operationalization and assessment period. While some indictors were based on self-constructed scales or items (e.g. parental illness, parental attention), others originated from standardized and valid measures with acceptable reliability (e.g. self-efficacy, chronic illness). Time-independent indicators (e.g. birth weight, prenatal exposure to smoking/drinking) and retrospective indicators (e.g. abuse/neglect, parental illness) have been answered only once while other information is available for at least two assessment periods (e.g. selfefficacy, social support). Information available at more than one measurement point was collapsed to form new indicators based on the time-variant nature (e.g. family instability) or to strengthen the indicator by using a within-person mean across several assessment periods (see Table 1, scale description for further information).

Furthermore, this study used information answered by parents (e.g. parental education status), along with combined information from parental reports for their children (age $<11$ years) and self-reports from adolescents and young adults (age $>10$ years), e.g., well-being in school and with peers. As not all risk factors are inherently dichotomous, the use of a cut point at the 75th percentile with $25 \%$ of the distribution towards a less favourable score changed risk variables into groups of absence and presence of risk. The approach to use binary variables was taken to facilitate the interpretation of latent classes and reduce the number of parameters estimated by the models [49].

\section{Mental health outcomes}

The KiGGS Cohort study provided self- and parentreported diagnoses of mental disorders, such as ADHD and depression. Parent and self-reported data of lifetime ADHD diagnoses given by a physician or psychologists were assessed at KiGGS Wave 2. Lifetime diagnoses of depression were reported by young adults (age $>18$ years) at KiGGS Wave 2. Mental health problems were assessed using a parent and self-reported Strengths and Difficulties Questionnaire (SDQ, [50]) at KiGGS Wave 2. Parents and children or adolescents answered several questions assessing symptoms on four subscales: conduct problems, emotional problems, hyperactivity, and peer problems within the last 12 months. The difficulties score for each subscale was calculated and banding scores were used to categorise into 'normal' vs. 'borderline / abnormal' scores [51,52].

Moreover, as suggested by Goodman, Lamping, \& Ploubidis [50], the SDQ allows a differentiation of mental 


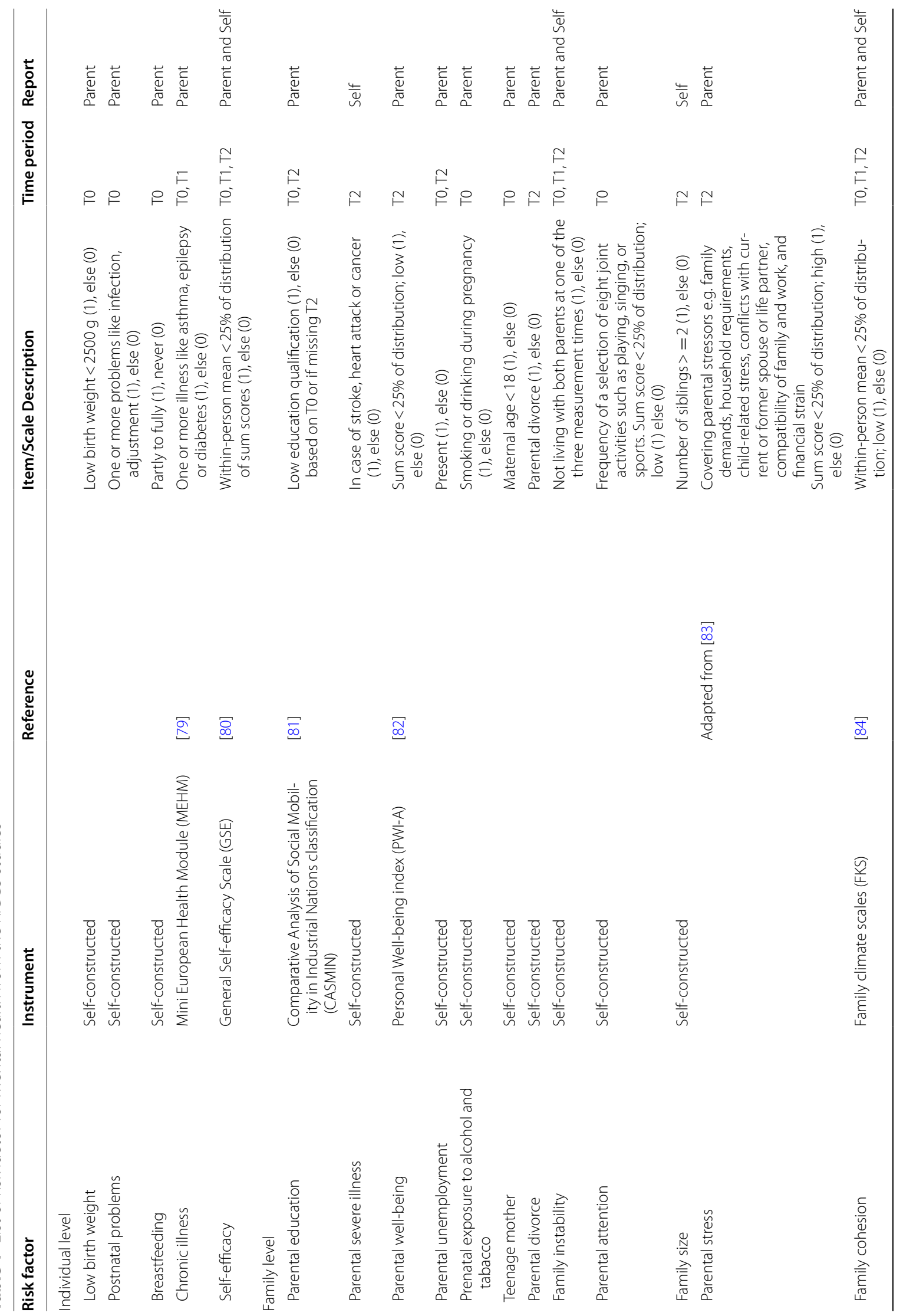




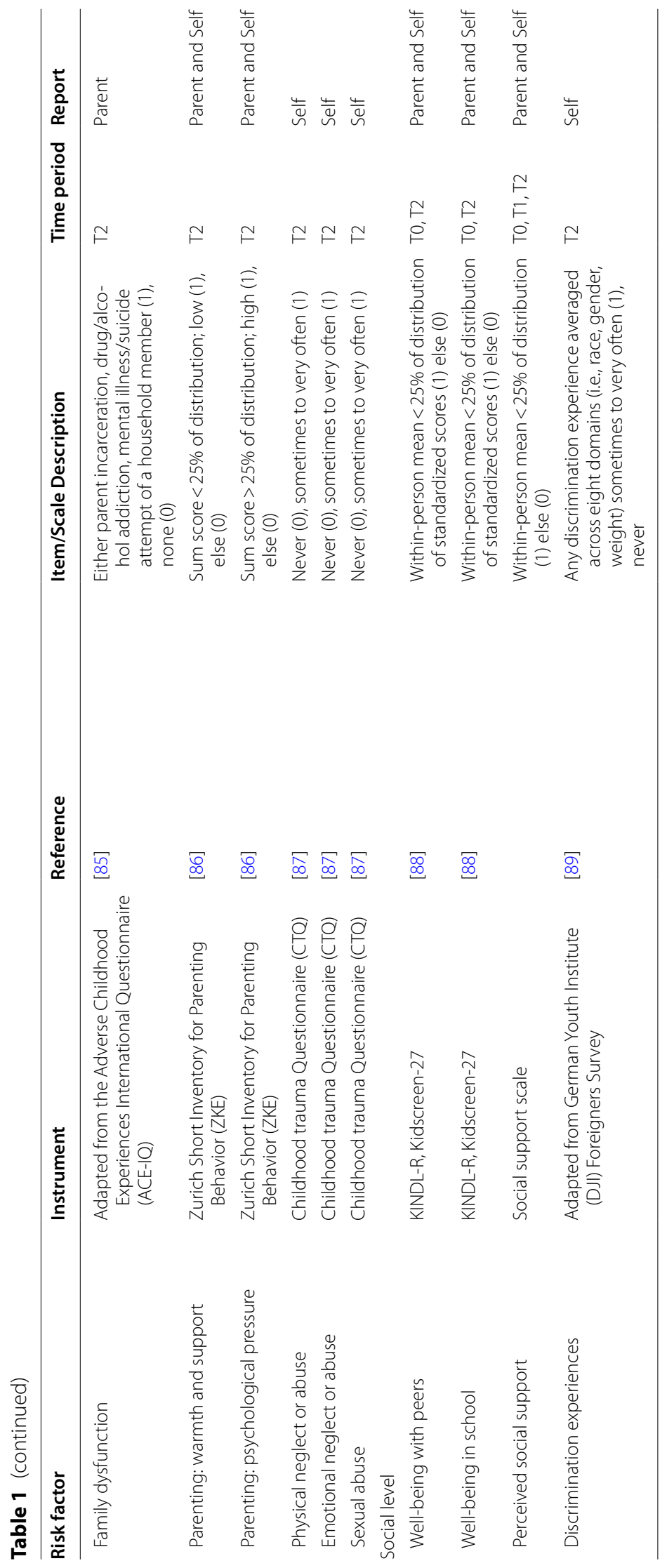


health problems into internalizing and externalizing problems. While internalizing behaviours (subscales emotional and peer problems) are described as socialemotional problems directed inwards related to social withdrawal, depression and anxiety, inversely externalizing behaviours (subscales conduct problems and hyperactivity) are described as behavioural problems directed outwards like hyperactivity, non-compliance, or aggression [53].

\section{Statistical analysis \\ Latent class analysis (LCA)}

LCA was applied using Mplus 7.1 to relate a set of observed indicators to the optimal number of subgroups with similar risk behavior profiles [54]. A set of 27 binary risk indicators for children's mental health infers latent class membership. The LCA processes almost 135 million possible patterns of unique responses for the given risk indicators into meaningful subgroups reflecting dominant profiles in the sample. A comprehensive overview of LCA can be found in Collins and Lanza [40].

In a first step, successive LCA models with ascending number of classes were examined and model selection was determined based on underlying statistical evidence and theoretical assumptions [55]. Subsequently, the appropriate number of latent classes relayed on several statistical criteria, including the Akaike information criterion (AIC), Bayesian information criterion (BIC), and the sample size-adjusted Bayesian criterion (aBIC). In addition, the entropy and posterior probabilities were examined for each model. To determine the number of classes in latent class analysis, the Lo-Mendell-Rubin test (LMRT) and the bootstrapped likelihood (BLRT) are used and provide a data-driven way to evaluate the relative adequacy of a (K-1)-class model compared to a K-class model. Missing data for the risk and protective factors varied between $0.46 \%$ (family instability) and $5.80 \%$ (postnatal problems). The missing rate for each variable was on average below $5 \%$ and, was addressed by using full information maximum likelihood (FIML) under the assumption of "missing at random" (MAR) available in Mplus.

\section{Multinomial logistic regression}

The last step builds upon the LCA "three-step" procedure by which following the model building process and the assignment to the latent classes or groups, a multinomial logistic regression model was estimated to include covariates (i.e. age and gender) and mental health outcomes (i.e. internalizing and externalizing mental health problems, diagnoses of ADHD and depression) to examine differences in the probabilities of each subgroup to be at risk for distinct mental health problems (for more information see [56]).

\section{Results}

\section{Descriptive statistics}

Distribution of risk factors in the sample population varies widely. While some risk factors are less pronounced in the sample, for instance teenage mothers $(0.31 \%)$ or low parental attention $(1.47 \%)$, others seem very common such as discrimination experiences (45.33\%) or a dysfunctional family life $(54.80 \%)$ (see Table 2).

A cumulative score of risk factors shows that $1.65 \%$ of individuals (mean age $=19, \mathrm{SD}=4.33$ ) in the sample endorsed no risk, while $0.09 \%$ of individuals (mean age $=20, \mathrm{SD}=4.32$ ) reported fifteen or more risk factors. On average, individuals reported four to five risk factors (mean $=4.90, \mathrm{SD}=2.67$ ) of mental health over a period of 11 years.

Table 2 Prevalence rates for each risk factor $(N=10,853)$

\begin{tabular}{|c|c|c|}
\hline Risk factors & $\%$ & $\mathrm{n}$ \\
\hline \multicolumn{3}{|l|}{ Individual level } \\
\hline Low Birth Weight & 5.51 & 583 \\
\hline Early infant problems & 20.50 & 2096 \\
\hline Breastfeeding & 19.04 & 2029 \\
\hline Chronic illness & 24.70 & 2681 \\
\hline Self-efficacy & 25.88 & 2726 \\
\hline \multicolumn{3}{|l|}{ Family level } \\
\hline Parental education & 12.68 & 1367 \\
\hline Parental severe illness & 35.93 & 3900 \\
\hline Parental well-being & 23.28 & 1037 \\
\hline Parental unemployment & 14.11 & 1531 \\
\hline Prenatal smoking or drinking & 25.60 & 2719 \\
\hline Teenage mother & 0.31 & 33 \\
\hline Parental divorce & 12.20 & 548 \\
\hline Family instability & 22.95 & 2479 \\
\hline Parental attention & 1.47 & 160 \\
\hline Large family size & 17.15 & 1861 \\
\hline Parental stress & 28.34 & 1250 \\
\hline Family cohesion & 30.74 & 3296 \\
\hline Family dysfunction & 54.80 & 5947 \\
\hline Parenting: warmth and support & 22.76 & 982 \\
\hline Parenting: psychological pressure & 28.16 & 1215 \\
\hline Physical neglect or abuse & 21.68 & 1317 \\
\hline Emotional neglect or abuse & 31.23 & 1897 \\
\hline Sexual abuse & 5.26 & 320 \\
\hline \multicolumn{3}{|l|}{ Social level } \\
\hline Well-being with peers & 27.06 & 2878 \\
\hline Well-being in school & 24.90 & 2609 \\
\hline Perceived social support & 21.95 & 2335 \\
\hline Discrimination experiences & 45.33 & 4920 \\
\hline
\end{tabular}




\section{Model selection and number of classes}

Mplus computed models with one through seven latent classes with multiple set of starting values. Table 3 shows fit indices for all classes. The six-class and sevenclass model were not identified well with no sufficient replication of best log-likelihood value. Results suggest that models with four or five latent classes could be considered based on LMRT and BLRT $\mathrm{p}$ values. The model quality based on the entropy showed little difference between solutions slightly favouring the 5 -class solution, however the posterior probabilities for the class membership was below 0.80 [57]. Moreover, the additional fifth class for the five-class model did not add more interpretive value compared to the four-class model. Based on the quality of the model, the interpretability of the latent classes, and the parsimony principle, we selected the four-class model as most optimal.
Figure 1 shows the probabilities of reporting each risk factor by class.

In general, few reported risk factors showed similar probabilities across classes (i.e. birth problems, LBW, breastfeeding and teenage mother) and therefore have little influence on class differentiation. Other risk factors, on the contrary, were more predominant by showing high variance regarding probability across classes. Precisely, most risk factors from the individual domain were less pronounced to differentiate classes compared to risk factors from the family and social domain.

Table 4 shows conditional probabilities of indicators of latent classes. All reported indicators below show significant differences among latent classes.

Class 1 (basic-risk) is composed of a high proportion of individuals $(51.4 \%)$ who are likely to report very few risk factors. Compared with members of the other classes,

Table 3 Summary of model fit indices of successive latent class models $(N=10,853)$

\begin{tabular}{|c|c|c|c|c|c|c|}
\hline Model & AIC & $\mathrm{BIC}$ & $\mathrm{aBIC}$ & Entropy & LMRT p value & BLRT $p$ value \\
\hline Two-class & $235,638.280$ & $236,053.935$ & $235,872.797$ & 0.618 & 0.000 & 0.000 \\
\hline Three-class & $232,624.262$ & $233,251.391$ & $232,978.094$ & 0.704 & 0.000 & 0.000 \\
\hline Four-class & $231,236.097$ & $232,074.700$ & $231,709.245$ & 0.750 & 0.000 & 0.000 \\
\hline Five-class & $230,389.630$ & $231,439.706$ & $230,982.093$ & 0.763 & 0.000 & 0.000 \\
\hline Six-class $^{\mathbf{a}}$ & $229,846.766$ & $231,108.316$ & $230,558.545$ & 0.725 & 0.000 & 0.000 \\
\hline Seven-class ${ }^{\mathbf{a}}$ & $229,480.724$ & $230,953.747$ & $230,311.818$ & 0.667 & 0.000 & 0.000 \\
\hline
\end{tabular}

AIC Akaike information criteria, BIC Bayesian information criteria, aBIC adjusted BIC; LMR LTR $p$ value Lo-Mendell-Rubin likelihood ratio test $\mathrm{p}$ value, $B L R T L R T p$ Bootstrapped Likelihood ratio test $\mathrm{p}$ value

Best-fitting model is indicatedin bold

${ }^{\text {a }}$ Latent class solution not well identified

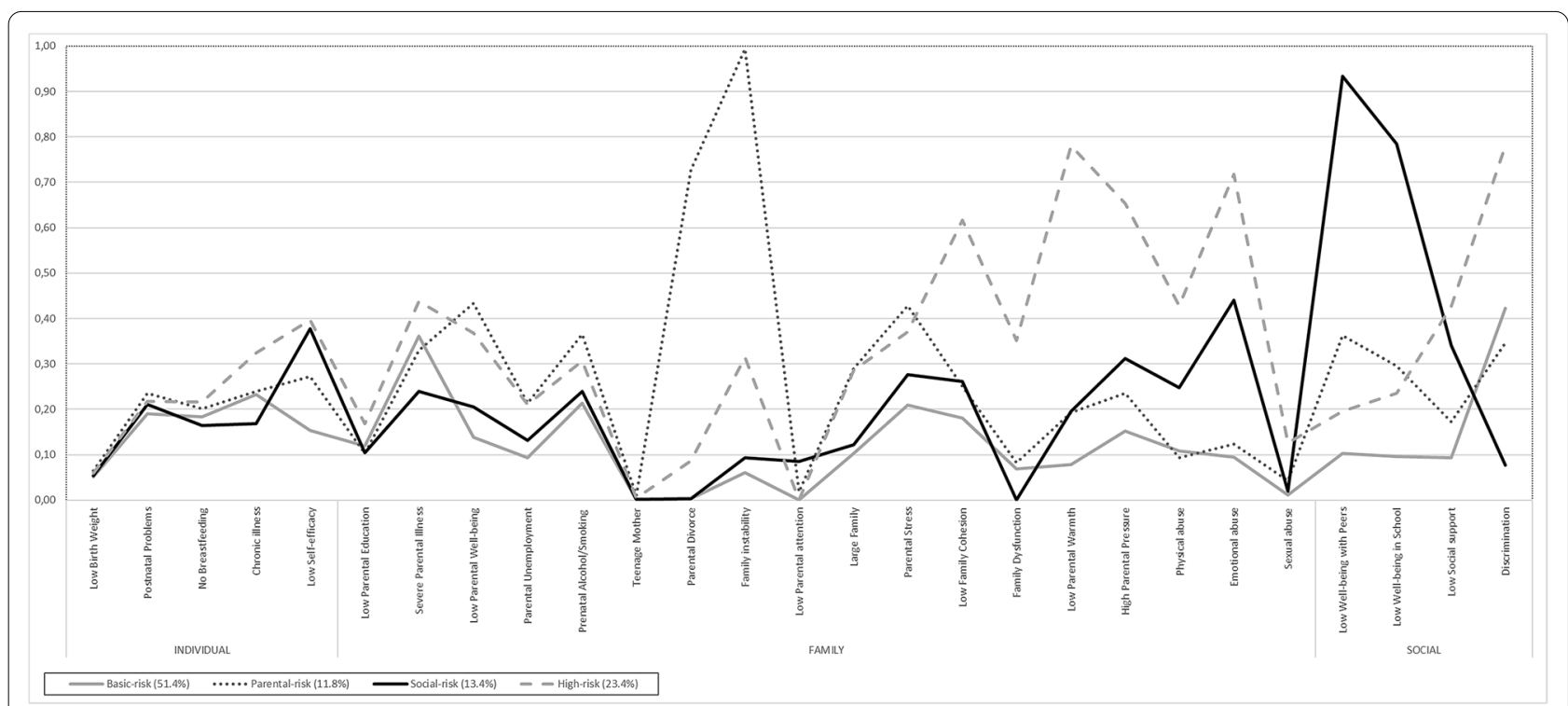

Fig. 1 Item probability for each latent class. The horizontal axis displays the 27 risk factors for mental health, while the vertical axis show the item probabilities of the four-class solution 
Table 4 Conditional probabilities of indicators by latent class

\begin{tabular}{|c|c|c|c|c|}
\hline Indicators & $\begin{array}{l}\text { Basic- } \\
\text { risk } \\
(51.4 \%)\end{array}$ & $\begin{array}{l}\text { Parental- } \\
\text { risk } \\
(11.8 \%)\end{array}$ & $\begin{array}{l}\text { Social- } \\
\text { risk } \\
(13.4 \%)\end{array}$ & $\begin{array}{l}\text { High- } \\
\text { risk } \\
(23.4 \%)\end{array}$ \\
\hline \multicolumn{5}{|l|}{ Individual level } \\
\hline Low Birth Weight & 0.051 & 0.065 & 0.054 & 0.059 \\
\hline Postnatal Problems & 0.191 & 0.235 & 0.211 & 0.218 \\
\hline No Breastfeeding & 0.183 & 0.201 & 0.165 & 0.216 \\
\hline Chronic illness & 0.233 & 0.24 & 0.168 & 0.324 \\
\hline Low Self-efficacy & 0.154 & 0.272 & 0.378 & 0.396 \\
\hline \multicolumn{5}{|l|}{ Family level } \\
\hline Low Parental Education & 0.119 & 0.103 & 0.104 & 0.168 \\
\hline Severe Parental IIIness & 0.361 & 0.330 & 0.240 & 0.438 \\
\hline Low Parental Well-being & 0.138 & 0.433 & 0.205 & 0.368 \\
\hline $\begin{array}{l}\text { Parental Unemploy- } \\
\text { ment }\end{array}$ & 0.094 & 0.213 & 0.132 & 0.211 \\
\hline $\begin{array}{l}\text { Prenatal Alcohol/Smok- } \\
\text { ing }\end{array}$ & 0.213 & 0.365 & 0.239 & 0.306 \\
\hline Teenage Mother & 0.001 & 0.010 & 0.002 & 0.005 \\
\hline Parental Divorce & 0.003 & 0.727 & 0.003 & 0.087 \\
\hline Family instability & 0.060 & 0.993 & 0.093 & 0.315 \\
\hline Low Parental attention & 0.001 & 0.018 & 0.085 & 0.000 \\
\hline Large Family & 0.103 & 0.290 & 0.122 & 0.286 \\
\hline Parental Stress & 0.209 & 0.428 & 0.277 & 0.371 \\
\hline Low Family Cohesion & 0.181 & 0.251 & 0.262 & 0.617 \\
\hline Family Dysfunction & 0.069 & 0.082 & 0.000 & 0.351 \\
\hline Low Parental Warmth & 0.079 & 0.193 & 0.196 & 0.781 \\
\hline High Parental Pressure & 0.152 & 0.235 & 0.312 & 0.653 \\
\hline Physical neglect/abuse & 0.108 & 0.093 & 0.248 & 0.428 \\
\hline $\begin{array}{l}\text { Emotional neglect/ } \\
\text { abuse }\end{array}$ & 0.095 & 0.124 & 0.44 & 0.718 \\
\hline Sexual abuse & 0.012 & 0.043 & 0.02 & 0.126 \\
\hline \multicolumn{5}{|l|}{ Social level } \\
\hline $\begin{array}{l}\text { Low Well-being with } \\
\text { Peers }\end{array}$ & 0.103 & 0.362 & 0.933 & 0.196 \\
\hline $\begin{array}{l}\text { Low Well-being in } \\
\text { School }\end{array}$ & 0.096 & 0.296 & 0.784 & 0.236 \\
\hline Low Social support & 0.093 & 0.172 & 0.341 & 0.427 \\
\hline Discrimination & 0.422 & 0.346 & 0.077 & 0.781 \\
\hline
\end{tabular}

individuals in this class were less likely to report low selfefficacy (15.4\%), low parental well-being (13.8\%), parental unemployment $(9.4 \%)$ or stress $(20.9 \%)$, and insufficient parenting (high pressure, less warmth). Additionally, members show more social support $(9.3 \%)$ and wellbeing with peers $(10.3 \%)$ and within school $(9.6 \%)$.

About half of all risk factors $(n=14)$ were reported by less than $10 \%$ of individuals with that class membership.

Class 2 (parental-risk) is composed of $11.8 \%$ of individuals with few reports on individual or social risk factors but with a focus on parent-related risks. Compared to other classes, almost all members (99.3\%) reported an unstable family structure (i.e. not living with both parents within the study period) and $72.7 \%$ of individuals experienced a parental divorce. Additionally, the class is characterized by the highest probability of parents reporting low well-being (43.3\%), parental stress $(42.8 \%)$ and prenatal exposure to alcohol and smoking (36.5\%).

Class 3 (social-risk) included individuals (13.4\%) likely to report risk factors from the social domain. Precisely, most class members showed a very low well-being with peers (93.3\%) and within school (78.4\%). Additionally, the class is composed of second highest proportion of individuals reporting high parental pressure (31.2\%), physical (24.8\%) and emotional (44\%) abuse or neglect.

Class 4 (high-risk) is the second largest class with $23.4 \%$. Class membership is characterized by individuals likely to report a large number of risk factors $(n=11)$ across all domains compared to the other classes. Most class members reported low family cohesion, high family dysfunction, insufficient parenting (i.e. low warmth und high pressure), child maltreatment (i.e. emotional neglect/ abuse, physical neglect/abuse and sexual abuse) and experiences with discrimination experience. Additionally, some individuals reported chronic illnesses (32.4\%), low parental education (16.8\%) and severe parental illnesses (43.8\%).

\section{Latent class membership prediction}

Table 5 shows prevalence rates and confidence intervals for age, gender and mental health outcomes within classes. Covariates (i.e. age, gender) and mental health outcomes (i.e. diagnoses of depression, ADHD,

Table 5 Prevalence rates and confidence intervals for age, gender and mental health outcomes

\begin{tabular}{lcccc}
\hline & Basic-risk (51.4\%) & Parental-risk (1 1.8\%) & Social-risk (13.4\%) & High-risk (23.4\%) \\
\hline Age $^{\mathrm{a}}$ & $20(4.72)$ & $18(4.99)$ & $13(3.46)$ & $22(4.44)$ \\
Gender (female) & $53.5(52.2,54.8)$ & $53.6(50.8,56.3)$ & $47.9(45.4,50.5)$ & $56.1(54.2,58.0)$ \\
Internalizing problems & $22.2(21.2,23.4)$ & $39.6(36.9,42.3)$ & $44.2(41.6,46.7)$ & $38.4(36.5,40.3)$ \\
Depression diagnosis & $2.8(2.4,3.3)$ & $2.7(1.9,3.8)$ & $0.7(0.4,1.3)$ & $13.3(12.1,14.7)$ \\
Externalizing problems & $19.2(18.2,20.3)$ & $34.5(31.9,37.1)$ & $41.1(38.6,43.6)$ & $32.2(30.4,34.1)$ \\
ADHD diagnosis & $4.2(3.7,4.8)$ & $8.6(7.2,10.3)$ & $6.9(5.7,8.3)$ & $9.4(8.3,10.5)$
\end{tabular}

${ }^{a}$ Mean (std), KiGGS Wave 2 


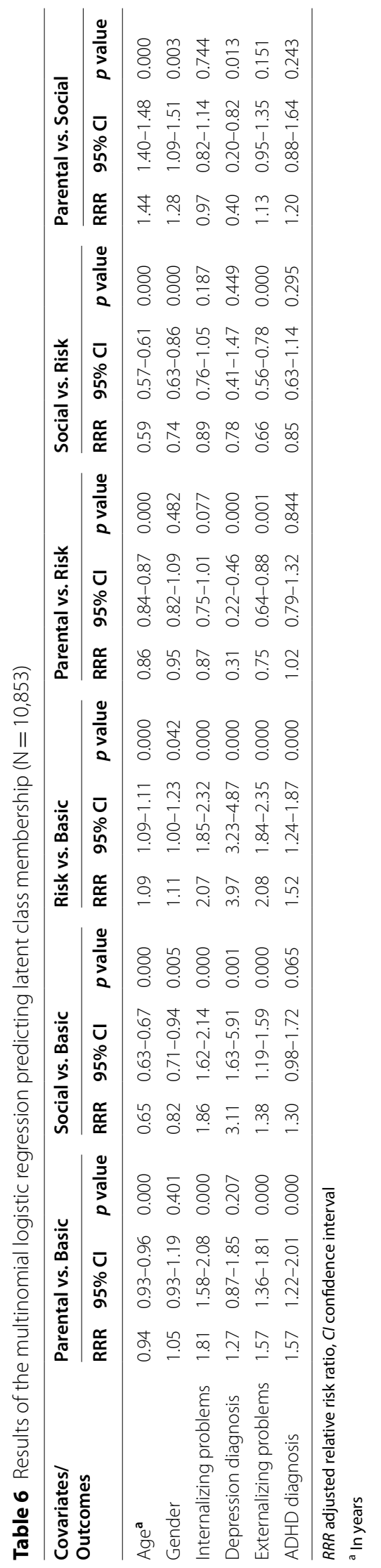


internalizing and externalizing mental health problems) showed significant associations with class membership (see Table 6). In general, social-risk class members are younger with more males compared to the other risk classes. In turn, high-risk class members are more likely to be older and female compared to the other classes. Compared to the basic-risk members, the parental-risk, social-risk and the high-risk class members had higher odds of having internalizing and externalizing mental health problems, depression and ADHD. Compared to the high-risk class members, social-risk class members showed lower odds for externalizing problems. Additionally, the parental-risk class showed lower odds for externalizing problems compared to the high-risk class and lower odds for depression diagnoses compared to the high-risk and social-risk class.

\section{Discussion}

This research investigated different profiles of multiple risk factors for mental health and their associations to less adaptive mental health outcomes.

To complement the general approach towards multiple risk factors using a variable-oriented method (i.e. cumulative risk index), a person-centered method was used to provide a clearer picture regarding the interplay of an individual's array of risk factors for mental health. The Latent class analysis (LCA) demonstrated different constellations of 27 risk factors across an individual, familial and social domain and their prediction of mental health problems, depression, and ADHD. In line with previous research and our prediction, a set of four risk classes was identified as optimal out of millions of possible combinations. Precisely, the analysis extracted classes not only characterized by the number of risk factors (e.g. low, medium, high) but also identified risk profiles based on very specific risk factor constellations. While a multiple risk index considers only the mere exposure of several risks, this person-centered approach highlights the specific nature of the risk factors and provides information about the interaction between risk factors and its variation across distinct subgroups.

\section{Differences between risk classes and associations with mental health outcomes}

In general, some risk factors showed small impact regarding the distinction between risk classes. For instance, individual risk factors (e.g. breastfeeding, LBW, postnatal problems) were less likely to be reported by the respondents. Albeit previous research has shown their relevance and contribution to negative mental health outcomes like developmental delays and behavioural disorders in children and adolescents [14, 18], individual factors are less dominant compared to adverse family-specific risks when it comes to children's mental health [9]. Results confirm the crucial role of family-specific risk factors across the extracted classes.

The largest class (basic-risk class; $51.4 \%$ ) showed a low profile of risk factors for mental health with two minor exceptions. More than $30 \%$ of class members stated to have experienced discrimination of some sort (e.g. appearance, weight) and reported a parent with severe illness (i.e. stroke, cancer, heart attack). As these findings correspond with the relatively high prevalence rates of discrimination or teasing from other national adolescent samples (e.g., Canada 25.7\%, [58]; US 24.3\%, [59]) and cardiovascular diseases such as stroke or heart attack evolved into the most prevalent adult illnesses and leading causes of death worldwide [60], the relatively high prevalence rates in the basic-risk class is not outstanding.

Furthermore, basic-risk class members are far less likely to show any kind of mental health problem or disorder (i.e. depression and ADHD) compared to the other risk classes. This may be related to the finding that basic-risk class members endorse other factors, which could help to compensate the negative effect of discrimination and distress about parental health, such as high self-efficacy, positive parenting (i.e. high amount of warmth and less pressure), high family cohesion and social support.

On the contrary, the other risk classes (i.e. high-risk, parental-risk and social-risk) do show less individuals endorsing factors, which could help to buffer negative effects, for instance social support, well-being in school and with peers. In general, high-risk class members are older and more likely to be female; moreover, they reported the highest number of risk factors among classes, particularly in the family domain. For instance, insufficient parenting (less parental warmth and high pressure) and child maltreatment are more prominent among members of the high-risk class. These results support previous research by highlighting the significance of the family life for mental health [9], as those risk class members also show a greater likelihood for mental health problems (i.e. internalizing and externalizing problems) and mental disorders (i.e., depression and ADHD) as compared to the other classes. Furthermore, discrimination (especially towards appearance, weight and gender) is reported by a large number of individuals (78.1\%) within the high-risk class. As females, who perceive more pressure regarding appearance and are more often victims of teasing by peers and family compared to males [61] are overrepresented in the high-risk class, the higher prevalence of individuals reporting discrimination is comprehensible. Weight-based teasing in adolescence from family members and peers seems to be a crucial factor for low self-esteem, emotional distress and depression [61, 62]. Additionally, a number of existing 
studies provided evidence that a history of abuse predicted increasing depressive symptoms only for females as they are more likely to cope with stress via an avoidant (or ruminative) coping style [63].

A multitude of studies exists with a focus on adversities, which are directly threatening and harmful for a child's development, for instance child maltreatment and violence [32]. Nevertheless, instability and unpredictability within the family life may also be unfavourable and damaging [64]. Family instability or the change in the family structure by divorce, remarriage, cohabitation, and union dissolution results in ambiguity and insecurity regarding boundries, goals, values and roles within the family [65]. Those changes are associated with an accumulation of stressors for parents and children, and moreover may provoke anxieties for children that persist into adulthood $[66,67]$. There are claims stating that parental divorce is one of the most stressful event during childhood with long lasting consequences [68].

Almost all individuals with a class membership in the smallest group (parental-risk) reported family instability and parental divorce. Additionally, class members showed an elevated risk for internalizing and externalizing problem behaviour and ADHD. Those findings are in line with previous research claiming that family instability is associated with negative cognitive and behavioural outcomes $[69,70]$. For this reason, it may be beneficial to present selective intervention strategies to improve resilience and coping strategies by directly working with children of divorce (e.g. [71, 72]). Mental health professionals are advised to work closely with the educational sectors such as primary care or schools to improve early detection of risk factors from infancy to childhood to adolescence, to provide treatment and to prevent manifestation of mental disorders.

The members of the social-risk class showed very specific risk factors in the social domain-well-being in school and with peers. However, as compared to the other risk classes, social-risk class members are younger and more likely to be males. Peer-related bullying behaviour or victimization as well as school-related conflicts may explain the difference between classes. For example, in the present study peer-related well-being comprises items of helping and relying on each other and schoolrelated well-being comprises items of getting along well with teachers or being satisfied in school. In general, boys report significantly more often being bullied compared to girls, moreover self-reported victimization declines with increasing age [73]. Younger children are more likely to report peer victimization as compared to older individuals. Additionally, research suggests that boys are more likely than girls to experience teacher-related conflict and disciplinary action in school $[74,75]$. Compared to the basic-risk class, all negative health outcomes (i.e. internalizing and externalizing problems and diagnoses of depression or ADHD) are more likely for the social-risk class members. Precisely, being a member of the socialrisk class triples the risk of being diagnosed with depression compared to the basic-risk group after controlling for age and gender. Several studies confirm the association of well-being in school or with peers on adverse mental health consequences [76, 77].

A few evidence-based and evaluated preventive intervention programmes proved to reduce bullying and relational aggression. For instance, the fairplayer.manual is a multicomponent preventive intervention programme with an emphasis on the group mechanisms of bullying, and therefore, intervening, at the school class level (for seventh to ninth graders) and is designed to address highrisk-group children or causal risk factors, respectively [78]. However, more efforts should be directed towards the implementation of such programmes to improve mental health of children and adolescence and prevent mental disorders, for instance focusing on nationwide rather than regional implementation.

While the study furthers the general understanding of the interaction between multiple risk factors from several domains and its influence on developmental health outcomes, certain limitations should be noted. First, some relevant risk-related variables were assessed retrospectively, elevating the risk for recall bias especially for information like breastfeeding routine or postnatal problems (e.g. excessive crying). Second, associations between risk classes and mental health outcomes cannot be considered as causal, but rather as a connection or mutual relationship between variables. Third, while most variables, like gender and lifetime prevalence, are inherently categorical, several continuous risk factors were dichotomized according to a cut-off by scoring the upper forth of the distribution and thus only represent rough estimators.

Finally, no predictions regarding transitions between classes or developmental trajectories are possible and may constitute the object of future studies. For instance, as life-time risk for certain factors increase with age and risk exposure changes with time, longitudinal measures of risk patterns would be a worthwhile future direction (e.g. using latent transition analysis).

\section{Conclusions}

Substantial research has shown that the exposure to an accumulation of various risk factors (called multiple risk perspective) relative to a single risk is associated with poorer mental health. Moreover, multiple risk research has commonly involved variable-centered approaches such as cumulative risk index. Although the approach demonstrated that a specific number of risk factors 
makes individuals more vulnerable towards negative mental health outcomes, results of a cumulative risk index does not help in targeting particular ecological domains (e.g. individual, familial, social) for prevention, intervention and health policies. The topic is of great importance, as children's functioning within the family and the peer environment have long-term developmental consequences for health, well-being, and achievement across adolescence and adulthood [45]. To complement this approach and to improve further understanding of the interplay between multiple risk factors, a personcentered method (e.g. LCA) was introduced. LCA allows for the identification of heterogeneous groups of individuals who share a particular combination of risk factors, which may help to better identify special treatment needs according to specific risk constellations. While an array of 27 risk factors seemed overwhelming in terms of preventive approaches, a four-class solution generated by the LCA provides a parsimonious and concise view of the interplay between those numerous risk factors and aids towards diverse prevention strategies. The understanding of multiple risk and different risk "profiles" helps to adjust interventions and its treatment specification by focusing on a particular vulnerable group, such as late adolescent girls with problems within their family or young males with difficulties in school and with peers. Furthermore, recent research shows that an effective prediction of children with greatest risk for aversive mental health may help to direct resources for intervention measures more successfully.

\section{Acknowledgements}

Not applicable

\section{Authors' contributions}

All authors contributed to the study conception and design. Material preparation, and analysis were performed by Kristin Göbel and Caroline Cohrdes. The first draft of the manuscript was written by Kristin Göbel and Caroline Cohres. All authors read and approved the final manuscript.

\section{Funding}

Open Access funding enabled and organized by Projekt DEAL. The study was funded by the German Ministry of Health (BMG) [grant number ZMV1-2516-FSB-703].

\section{Availability of data and materials}

Not applicable.

\section{Declaration}

Ethics approval and consent to participate

KiGGS complies with the data protection provisions set out in the Federal Data Protection Act and the Charité - Universitätsmedizin Berlin's ethics committee assessed the ethics of the KiGGS baseline study (No. 101/2000) and KiGGS Wave 1 (No. EA2/058/09), Hannover Medical School's ethics committee assessed KiGGS Wave 2 (No. 2275-2014).

\section{Consent for publication}

Not applicable.

\section{Competing interests}

The authors declare that they have no competing interests.

\section{Author details}

${ }^{1}$ Department of Epidemiology and Health Monitoring, Mental Health Unit, Robert Koch Institute, General-Pape-Straße 62-66, 12101 Berlin, Germany. ${ }^{2}$ Present Address: Department of Educational Science and Psychology, Division of Developmental Science and Applied Developmental Psychology, Freie Universität Berlin, Habelschwerdter Allee 45, 14195 Berlin, Germany.

Received: 28 October 2020 Accepted: 1 June 2021

Published online: 14 June 2021

\section{References}

1. Kieling C, Baker-Henningham H, Belfer M, Conti G, Ertem I, Omigbodun O, et al. Child and adolescent mental health worldwide: evidence for action. The Lancet. 2011;378(9801):1515-25.

2. Hofstra MB, Van Der Ende J, Verhulst FC. Child and adolescent problems predict DSM-IV disorders in adulthood: a 14-year follow-up of a Dutch epidemiological sample. J Am Acad Child Adolesc Psychiatry. 2002;41(2):182-9.

3. World Health Organization. Global Health Estimates 2015: Disease burden by cause, age, sex, by country and by region, 2000-2015. www.who.int/ entity/healthinfo/global_burden_disease/GHE2015_YLD_Global_2000_ 2015.xls?ua $=1.2016$

4. Polanczyk G, De Lima MS, Horta BL, Biederman J, Rohde LA. The worldwide prevalence of ADHD: a systematic review and metaregression analysis. Am J Psychiatry. 2007;164(6):942-8.

5. Evans GW, Li D, Whipple SS. Cumulative risk and child development. Psychol Bull. 2013;139(6):1342.

6. Liaw F-R, Brooks-Gunn J. Cumulative familial risks and low-birthweight children's cognitive and behavioral development. J Clin Child Psychol. 1994;23(4):360-272.

7. Appleyard K, Egeland B, van Dulmen MH, Sroufe LA. When more is not better: the role of cumulative risk in child behavior outcomes. J Child Psychol Psychiatry. 2005;46(3):235-45.

8. Rutter M. Protective factors in children's responses to stress and disadvantage. Ann Acad Med Singapore. 1979;8(3):324-38.

9. Wille N, Bettge S, Ravens-Sieberer U, Bella Study Group. Risk and protective factors for children's and adolescents' mental health: results of the BELLA study. Eur Child Adolesc Psychiatry. 2008;17(Supp11):133-47.

10. Lövdén M, Bergman L, Adolfsson R, Lindenberger U, Nilsson L-G. Studying individual aging in an interindividual context: typical paths of agerelated, dementia-related, and mortality-related cognitive development in old age. Psychol Aging. 2005;20(2):303-16.

11. Patel V, Flisher AJ, Hetrick S, McGorry P. Mental health of young people: a global public-health challenge. The Lancet. 2007;369(9569):1302-13.

12. Moksnes UK, Reidunsdatter RJ. Self-esteem and mental health in adolescents-level and stability during a school year. Norsk Epidemiologi. 2019. https://doi.org/10.5324/nje.v28i1-2.3052.

13. Schwarzer R. Optimistische Kompetenzerwartung: Zur Erfassung einer personalen Bewältigungsresource [Generalized self-efficacy: Assessment of a personal coping resource]. Diagnostica. 1994;40(2):105-23.

14. Foulon S, Pingault JB, Larroque B, Melchior M, Falissard B, Cote SM. Developmental predictors of inattention-hyperactivity from pregnancy to early childhood. PLoS ONE. 2015;10(5):e0125996.

15. Williams JH, Ross L. Consequences of prenatal toxin exposure for mental health in children and adolescents. Eur Child Adolesc Psychiatry. 2007;16(4):243-53.

16. Julvez J, Ribas-Fitó N, Forns M, Garcia-Esteban R, Torrent M, Sunyer J. Attention behaviour and hyperactivity at age 4 and duration of breastfeeding. Acta Paediatr. 2007;96(6):842-7.

17. Hysing M, Elgen I, Gillberg C, Lie SA, Lundervold AJ. Chronic physical illness and mental health in children. Results from a large-scale population study. J Child Psychol Psychiatry. 2007;48(8):785-92.

18. Douglas P, Hill P. Managing infants who cry excessively in the first few months of life. BMJ. 2011;343:d7772. 
19. Wake M, Morton-Allen E, Poulakis Z, Hiscock H, Gallagher S, Oberklaid F. Prevalence, stability, and outcomes of cry-fuss and sleep problems in the first 2 years of life: prospective community-based study. Pediatrics. 2006;117(3):836-42

20. Trentacosta CJ, Hyde LW, Shaw DS, Dishion TJ, Gardner F, Wilson M. The relations among cumulative risk, parenting, and behavior problems during early childhood. J Child Psychol Psychiatry. 2008;49(11):1211-9.

21. Carlson MJ, Corcoran ME. Family structure and children's behavioral and cognitive outcomes. J Marriage Fam. 2001;63:779-92.

22. Lamborn SD, Mounts NS, Steinberg L, Dornbusch SM. Patterns of competence and adjustment among adolescents from authoritative, authoritarian, indulgent, and neglectful families. Child Dev. 1991;62(5):1049-65.

23. Fomby $P$, Cherlin AJ. Family instability and child well-being. Am Sociol Rev. 2007;72(2):181-204.

24. Freitas GV, Cais CF, Stefanello S, Botega NJ. Psychosocial conditions and suicidal behavior in pregnant teenagers : a case-control study in Brazil. Eur Child Adolesc Psychiatry. 2008;17(6):336-42.

25. Carballo JJ, Garcia-Nieto R, Alvarez-Garcia R, Caro-Canizares I, Lopez-Castroman J, Munoz-Lorenzo L, et al. Sibship size, birth order, family structure and childhood mental disorders. Soc Psychiatry Psychiatr Epidemiol. 2013;48(8):1327-33.

26. Russell AE, Ford T, Russell G. Socioeconomic associations with ADHD: findings from a mediation analysis. PLoS ONE. 2015;10(6):e028248.

27. Hardie JH, Landale NS. Profiles of risk: maternal health, socioeconomic status, and child health. J Marriage Fam. 2013;75(3):651-66.

28. Hintermair M. Parental resources, parental stress, and socioemotional development of deaf and hard of hearing children. J Deaf Stud Deaf Educ. 2006;11(4):493-513.

29. Fulco CJ, Augustyn MB, Henry KL. Maternal depressive symptoms and adolescent health risk problems: the role of school engagement. J Youth Adolesc. 2019:49(1):102-18.

30. Goodman SH, Connell AM, Hall CM, Rouse MH, Robbins Broth M, Heyward D. Maternal depression and child psychopathology: a meta-analytic review. Clin Child Fam Psychol Rev. 2011;14:1-27.

31. Lara C, Fayyad J, de Graaf R, Kessler RC, Aguilar-Gaxiola S, Angermeyer $M$, et al. Childhood predictors of adult attention-deficit/hyperactivity disorder: results from the World Health Organization World Mental Health Survey Initiative. Biol Psychiatry. 2009;65(1):46-54.

32. Mills R, Scott J, Alati R, O'Callaghan M, Najman JM, Strathearn L. Child maltreatment and adolescent mental health problems in a large birth cohort. Child Abuse Negl. 2013;37(5):292-302.

33. Cohrdes C, Mauz E. Self-efficacy and emotional stability buffer negative effects of adverse childhood experiences on young adult health-related quality of life. J Adolesc Health. 2020;67(1):93-100.

34. Hamarman S, Bernet W. Evaluating and reporting emotional abuse in children: parent-based, action-based focus aids in clinical decision-making. J-Am Acad Child Adolesc Psychiatry. 2000;39(7):928-30.

35. Dekovic M. Risk and protective factors in the development of problem behavior during adolescence. J Youth Adolesc. 1999;28(6):667-85.

36. Pascoe EA, Smart RL. Perceived discrimination and health: a meta-analytic review. Psychol Bull. 2009;135(4):531.

37. Zuba A, Warschburger P. The role of weight teasing and weight bias internalization in psychological functioning: a prospective study among school-aged children. Eur Child Adolesc Psychiatry. 2017;26(10):1245-55.

38. Wickrama KAS, O'Neal CW, Lee TK. Cumulative socioeconomic adversity, developmental pathways, and mental health risks during the early life course. Emerg Adulthood. 2016;4(6):378-90.

39. Lanza ST, Rhoades BL, Nix RL, Greenberg MT. Modeling the interplay of multilevel risk factors for future academic and behavior problems: a person-centered approach. Dev Psychopathol. 2010;22(2):313-35.

40. Collins LM, Lanza ST. Latent class and latent transition analysis: with applications in the social, behavioral, and health sciences. Wiley; 2009

41. Walrath CM, Petras H, Mandell DS, Stephens RL, Holden EW, Leaf PJ. Gender differences in patterns of risk factors among children receiving mental health services: Latent class analyses. J Behav Health Serv Res. 2004;31(3):297-311.

42. Göbel $K$, Scheithauer $H$, Braker AB, Jonkman $H$, Soellner R. Substance use patterns among adolescents in europe: a latent class analysis. Subst Use Misuse. 2016;51(9):1130-8.
43. Ling Y, Huebner ES, He Y-S, Zhong M-T. Three subtypes of internalizing and externalizing behaviors in Chinese adolescents: results of a latent class analysis. Appl Res Qual Life. 2016;11(4):1309-20.

44. Schultze-Krumbholz A, Göbel K, Scheithauer H, Brighi A, Guarini A, Tsorbatzoudis $\mathrm{H}$, et al. A comparison of classification approaches for cyberbullying and traditional bullying using data from six European countries. J Sch Violence. 2014;14(1):47-65.

45. Parra GR, DuBois DL, Sher KJ. Investigation of profiles of risk factors for adolescent psychopathology: a person-centered approach. J Clin Child Adolesc Psychol. 2006;35(3):386-402.

46. Fanti KA, Henrich CC. Trajectories of pure and co-occurring internalizing and externalizing problems from age 2 to age 12: findings from the National Institute of Child Health and Human Development Study of Early Child Care. DP. 2010;46(5):1159.

47. Lange M, Hoffmann R, Mauz E, Houben R, Gößwald A, Schaffrath Rosario A, et al. KiGGS Wave 2 longitudinal component-data collection design and developments in the numbers of participants in the KiGGS cohort. J Health Monit. 2018;3:92-107.

48. Mauz E, Gößwald A, Kamtsiuris P, Hoffmann R, Lange M, Von Schenck $U$, et al. New data for action. Data collection for KiGGS Wave 2 has been completed. J Health Monit. 2017;2:2-27.

49. Nylund KL. Latent transition analysis: Modeling extensions and an application to peer victimization [Doctoral dissertation]. University of California, Los Angeles, USA; 2007. https://citeseerx.ist.psu.edu/viewdoc/ download?doi=10.1.1.310.4138\&rep=rep1\&type $=$ pdf.

50. Goodman A, Lamping DL, Ploubidis GB. When to use broader internalising and externalising subscales instead of the hypothesised five subscales on the Strengths and Difficulties Questionnaire (SDQ): data from British parents, teachers and children. J Abnorm Child Psychol. 2010;38(8):1179-91.

51. Woerner W, Becker A, Rothenberger A. Normative data and scale properties of the German parent SDQ. Eur Child Adolesc Psychiatry. 2004;13(2):ii3-10.

52. Becker A, Wang B, Kunze B, Otto C, Schlack R, Hölling H, et al. Normative data of the self-report version of the German Strengths and Difficulties Questionnaire in an epidemiological setting. Zeitschrift für Kinder-und Jugendpsychiatrie und Psychotherapie. 2018;46(6):523-33.

53. Yong M, Fleming CB, McCarty CA, Catalano RF. Mediators of the associations between externalizing behaviors and internalizing symptoms in late childhood and early adolescence. J Early Adolesc. 2014;34(7):967-1000.

54. Muthén LK, Muthén BO. Mplus user's guide: statistical analysis with Latent variables (7th ed.). Muthén M, editor. Los Angeles, CA; 1998-2012.

55. Nylund K, Bellmore A, Nishina A, Graham S. Subtypes, severity, and structural stability of peer victimization: what does latent class analysis say? CD. 2007;78(6):1706-22.

56. Vermunt JK. Latent class modeling with covariates: two improved threestep approaches. Polit Anal. 2010;18(4):450-69.

57. Geiser C. Data analysis with Mplus (series: methodology in the social sciences). New York: Guilford press; 2012.

58. Romano E, Bell T, Billette J-M. Prevalence and correlates of multiple victimization in a nation-wide adolescent sample. Child Abuse Negl. 2011;35(7):468-79.

59. Finkelhor D, Ormrod $R$, Turner $H$, Hamby SL. The victimization of children and youth: a comprehensive, national survey. Child Maltreat. 2005:10(1):5-25.

60. Fuster V, Kelly BB. Committee on preventing the global epidemic of cardiovascular disease: meeting the challenges in developing countries board on global health. Kelly, editors. 2010.

61. Helfert S, Warschburger P. The face of appearance-related social pressure: gender, age and body mass variations in peer and parental pressure during adolescence. Child Adolesc Psychiatry Ment Health. 2013;7:16.

62. Puhl RM, Wall MM, Chen C, Bryn Austin S, Eisenberg ME, NeumarkSztainer D. Experiences of weight teasing in adolescence and weightrelated outcomes in adulthood: a 15-year longitudinal study. Prev Med. 2017;100:173-9.

63. Cohen JR, Thomsen KN, Racioppi A, Ballespi S, Sheinbaum T, Kwapil TR, et al. Emerging adulthood and prospective depression: a simultaneous test of cumulative risk theories. J Youth Adolesc. 2019:48(7):1353-64. 
64. Coe JL, Parade SH. Family instability as a unique risk factor for children's adjustment problems. Brown Univ Child Adolesc Behav Lett. 2019:35(11):1-6.

65. McCubbin HI, Patterson JM. The family stress process: the double ABCX model of adjustment and adaptation. Marriage Fam Rev. 1983;6(1-2):7-37.

66. Gaydosh L, Harris KM. Childhood family instability and young adult health. J Health Soc Behav. 2018;59(3):371-90.

67. Beck AN, Cooper CE, McLanahan S, Brooks-Gunn J. Partnership transitions and maternal parenting. J Marriage Fam. 2010;72(2):219-33.

68. Stadelmann S, Perren S, Groeben M, von Klitzing K. Parental separation and children's behavioral/emotional problems: the impact of parental representations and family conflict. Fam Process. 2010;49(1):92-108.

69. Lee D, McLanahan S. Family structure transitions and child development: Instability, selection, and population heterogeneity. Am Sociol Rev. 2015;80(4):738-63.

70. Craigie T-AL, Brooks-Gunn J, Waldfogel J. Family structure, family stability and outcomes of five-year-old children. Fam Relatsh Soc. 2012;1(1):43-61.

71. Brand C, Howcroft G, Hoelson CN. The voice of the child in parental divorce: implications for clinical practice and mental health practitioners. J Child Adolesc Ment Health. 2017;29(2):169-78.

72. Sands A, Thompson EJ, Gaysina D. Long-term influences of parental divorce on offspring affective disorders: a systematic review and metaanalysis. J Affect Disord. 2017;218:105-14.

73. Scheithauer H, Hayer T, Petermann F, Jugert G. Physical, verbal, and relational forms of bullying among German students: age trends, gender differences, and correlates. Aggress Behav. 2006;32(3):261-75.

74. Koepke MF, Harkins DA. Conflict in the classroom: gender differences in the teacher-child relationship. Early Educ Dev. 2008;19(6):843-64

75. Wallace JM Jr, Goodkind S, Wallace CM, Bachman JG. Racial, ethnic, and gender differences in school discipline among US high school students: 1991-2005. Negro Educ Rev. 2008;59(1-2):47.

76. Bond L, Butler H, Thomas L, Carlin J, Glover S, Bowes G, et al. Social and school connectedness in early secondary school as predictors of late teenage substance use, mental health, and academic outcomes. J Adolesc Health. 2007:40(4):357 e9-18.

77. Foster CE, Horwitz A, Thomas A, Opperman K, Gipson P, Burnside A, et al. Connectedness to family, school, peers, and community in socially vulnerable adolescents. Child Youth Serv Rev. 2017;81:321-31.

78. Scheithauer H, Hess M, Schultze-Krumbholz A, Bull HD. School-based prevention of bullying and relational aggression in adolescence: The fairplayer manual. New Dir Youth Dev. 2012;2012(133):55-70.

79. Cox B, Oyen HV, Cambois E, Jagger C, Roy SI, Robine J-M, Romieu I. The reliability of the Minimum European Health Module. Int J Public Health. 2009;54(2):55-60. https://doi.org/10.1007/s00038-009-7104-y.
80. Schwarzer R, Jersusalem M. Generalized self-efficacy scale. In: Weinman J, Wright S, Johnston M, editors. Measures in health psychology: A user's portfolio Causal and control beliefs. 1. Windsor, UK: NFER-NELSON; 1995 p. 35-7.

81. König W, Lüttinger P, Müller W. A comparative analysis of the development and structure of educational systems: Methodological foundations and the construction of a comparative educational scale. Universität München, Institut für Sozialwissenschaften; 1988.

82. Cummins RA, Eckersley R, Pallant J, Van Vugt J, Misajon R. Developing a national index of subjective wellbeing: The Australian Unity Wellbeing Index. Social Indicators Res. 2003;64(2):159-90. https://doi.org/10.1023/A: 1024704320683.

83. Sperlich S, Arnhold-Kerri S, Geyer S. Soziale Lebenssituation und Gesundheit von Müttern in Deutschland. Social living conditions and health among mothers in Germany. Bundesgesundheitsblatt - Gesundheitsforschung - Gesundheitsschutz. 2011;54(6):735-44. https://doi.org/10. 1007/s00103-011-1283-4.

84. Schneewind KA. Die Familienklimaskalen (FKS). In: Cierpka M, editor. Familiendiagnostik. Berlin, Heidelberg: Springer; 1988. p. 232-55.

85. World Health Organization (WHO). Adverse Childhood Experiences International Querstionnaire (ACE-IQ); 2018. https://www.who.int/violence_ injury_prevention/violence/activities/adverse_childhood_experiences/ en/.

86. Reitzle M, Winkler C, Steinhausen HC. Eltern und Kinder: Der Zürcher Kurzfragebogen zum Erziehungsverhalten (ZKE). Diagnostica 2001;47(4):196-207. https://doi.org/10.1026//0012-1924.47.4.196.

87. Bernstein DP, Stein JA, Newcomb MD, Walker E, Pogge D, Ahluvalia T, Stokes J, Handelsman L, Medrano M, Desmond D, Zule W. Development and validation of a brief screening version of the Childhood Trauma Questionnaire. Child Abuse \& Neglect. 2003;27(2):169-90. https://doi.org/ 10.1016/S0145-2134(02)00541-0.

88. Ravens-Sieberer U, Wille N, Bettge S, Erhart M. Psychische Gesundheit von Kindern und Jugendlichen in Deutschland. Ergebnisse aus der BELLAStudie im Kinder- und Jugendgesundheitssurvey (KiGGS) [Mental health of children and adolescents in Germany. Results from the BELLA study within the German Health Interview and Examination Survey for Children and Adolescents (KiGGS)]. Bundesgesundheitsblatt 2007;50(5-6):871-8.

89. Deutsches Jugendinstitut (DJI). DJ Foreigner Survey - Young People, GESIS Data Archive, 1.0.0; 2001. https://doi.org/10.4232/1.3371.

\section{Publisher's Note}

Springer Nature remains neutral with regard to jurisdictional claims in published maps and institutional affiliations.
Ready to submit your research? Choose BMC and benefit from:

- fast, convenient online submission

- thorough peer review by experienced researchers in your field

- rapid publication on acceptance

- support for research data, including large and complex data types

- gold Open Access which fosters wider collaboration and increased citations

- maximum visibility for your research: over $100 \mathrm{M}$ website views per year

At BMC, research is always in progress.

Learn more biomedcentral.com/submissions 